\title{
O ATEÍSMO NA HISTORIOGRAFIA
}

\author{
The atheism in historiography
}

Ricardo Oliveira da Silva ${ }^{1}$

\begin{abstract}
RESUMO
Apresentar um panorama da produção historiográfica sobre o ateísmo é o principal objetivo desse trabalho. O dossiê História, Laicidade e Ateísmo, publicado pela revista Relegens Thréskeia procura preencher uma lacuna nos estudos sobre descrença religiosa nas ciências sociais brasileira, os quais ainda são escassos. Aproveitando a oportunidade eu enfatizo o potencial desse tipo de pesquisa para a historiografia brasileira. Com esse objetivo eu mostro inicialmente algumas investigações na historiografia estrangeira (até como forma de estimular os pesquisadores nacionais). E finalizo com a exposição de alguns estudos na universidade brasileira.
\end{abstract}

Palavras-chaves: ateísmo, história, historiografia.

\section{ABSTRACT}

The main objective of this work is to present an overview of historiographical production on atheism. The dossier História, Laicidade e Ateísmo [History, Laicity, and Atheism] published by the magazine Relegens Thréskeia seeks to fill a gap in studies on religious disbelief in the brazilian social sciences, which are still scarce. Taking the opportunity, I emphasize the potential of this type of research for brazilian historiography. With this objective in mind, I initially show some investigations in foreign historiography (even as a way to stimulate national researchers). And I conclude with the introduction to some studies at Brazilian academia.

Keywords: atheism, history, historiography.

\section{INTRODUÇÃO}

A descrença na existência de divindades que habitam uma realidade sobrenatural, e que nas religiões de matriz abraâmicas são concebidas na forma de um Deus único, criador do mundo e responsável por intervir e oferecer um sentido ao destino humano, e a consequente construção de uma visão de mundo não-religiosa, é um fenômeno que ainda não obteve um espaço apreciável nas pesquisas realizadas na área das ciências sociais brasileira. Em decorrência dessa realidade eu considero de extrema relevância à publicação do dossiê História, Laicidade e Ateísmo pela revista Relegens Thréskeia. Uma iniciativa que, ao contar com artigos de várias áreas do conhecimento, é um convite para que o tema das ações e visões de mundo

\footnotetext{
${ }^{1}$ Doutor em História pela Universidade Federal do Rio Grande do Sul (UFRGS). Docente do Curso de História da Universidade Federal do Mato Grosso do Sul, campus de Nova Andradina (UFMS/CPNA). E-mail: ricardorussell@gmail.com 
sem viés religioso, seja visto com mais atenção. E nesse convite eu gostaria de incluir a área da historiografia.

A historiografia, como definiu Michel de Certeau (2008), envolve a relação entre um lugar (um meio, uma profissão), procedimentos de análise (uma disciplina) e a construção de um texto (uma escrita). Jörn Rüsen (2007), por sua vez, destacou que a historiografia pode ser caracterizada como o processo da constituição narrativa de sentido, na qual o saber histórico é inserido, mediante uma narrativa, nos processos comunicativos da vida humana prática. No Brasil, esse perfil historiográfico se consolidou na segunda metade do século XX dentro das universidades, o que permitiu o estudo de diversos âmbitos da realidade social do país (LAPA, 1985).

Contudo, o ateísmo ainda hoje ocupa pouco espaço nas pesquisas historiográficas brasileiras. De acordo com Rafael Rodrigues da Silva (2007), é preciso considerar que a sociedade brasileira possui uma forte tradição religiosa, decorrente da colonização portuguesa. Essa tradição, até os dias de hoje predominantemente cristão-católica, molda comportamentos, formas de pensar e agir. Em decorrência disso, não é de estranhar que o tema da religião e das práticas religiosas tenha obtido grande atenção por parte dos historiadores. Por outro lado, como destaca Denise dos Santos Rodrigues (2012), a descrença religiosa como fenômeno histórico com certa amplitude social é algo recente, como mostram os dados do IBGE ao indicarem que a parcela da população que se identifica como sem religião foi de 1\% em 1980 para 8\% em 2010.

O objetivo desse artigo é mostrar exemplos de produções historiográficas sobre o ateísmo. No caso brasileiro eu me deparei com poucas pesquisas, e todas elas produzidas em anos recentes, quando o fenômeno do ateísmo começou a se fazer mais presente no espaço público e na internet. Diante disso, eu optei por dividir o artigo em duas partes: na primeira, quis mostrar as pesquisas produzidas em outros países e ainda não traduzidas e publicadas no Brasil. Com isso, busquei ressaltar que o ateísmo é um tema profícuo para os historiadores; na segunda parte, o foco foi direcionado para os trabalhos de caráter historiográficos feitos aqui no país.

\section{O ATEÍSMO NA HISTORIOGRAFIA ESTRANGEIRA}

Existem duas obras de história traduzidas em língua portuguesa que merecem atenção dos historiadores brasileiros. Uma delas é Breve história do ateísmo ocidental, publicada originalmente em 1971 por James Thrower. De acordo com ele (1982), o ateísmo estaria 
vinculado a uma concepção naturalista de mundo, ou seja, a ideia de que existiria apenas o mundo natural. Essa tradição intelectual teria surgido no Ocidente, especificamente na Grécia Antiga, com os filósofos pré-socráticos no século VI antes da era cristã. Já a segunda obra é História do ateísmo, publicada originalmente em 1998 por Georges Minois. Nas páginas deste livro a história do ateísmo é concebida de forma independente da história das religiões, como a "tentativa do homem de criar um sentido para si mesmo, de justificar para si mesmo sua presença no universo material, de nele construir um lugar inexpugnável.” (MINOIS, 2014, p. 04).

Um fato que me chamou atenção ao ler esses dois livros foi a afirmação sobre a pouca quantidade de pesquisas históricas sobre o tema do ateísmo. Segundo James Thrower (1982, p. 15) “[...] esta história da descrença, que está ainda por fazer e da qual praticamente não existem registros, que pretendo examinar nas páginas que se seguem.” E, nas palavras de Georges Minois (2014, p. 01), “[...] foi precisamente esse dilúvio de livros sobre a fé que suscitou meu interesse pelo campo da descrença, que continua sendo muito pouco estudado numa perspectiva histórica.” Até pouco tempo atrás, eu me deparava com a angústia dessa exiguidade. Mais recentemente, porém, comecei a encontrar novas produções historiográficas. Essas descobertas evidenciaram a viabilidade do estudo histórico sobre a descrença religiosa, o que pode estimular a comunidade de historiadores brasileiros. Gostaria de elencar abaixo alguns dos trabalhos que tive acesso.

O primeiro é A history of marxista-leninist atheism and soviet antireligious policies. Este livro foi publicado em três volumes entre 1987 e 1988 pelo historiador Dimitry V. Pospielovsky. De acordo com ele (1987, p. IX-X, tradução minha): “O objetivo principal deste estudo é uma apresentação passo a passo e uma análise da mudança de estilos, estratégias e táticas do ataque sem fim soviético à religião e aos religiosos.” Dimitry V. Pospielovsky ressalta a influência do ateísmo filosófico marxista-leninista, o qual preconizava o fim da religião com o advento de uma sociedade sem classes construída pelos trabalhadores, nas políticas contra as instituições e os credos religiosos criadas pelos bolcheviques a partir da Revolução Russa de 1917.

Por ser uma obra datada ainda no período de existência da União Soviética, realidade política que deixou de existir oficialmente em 1991, o autor enfatizou a dificuldade de acesso as fontes, limitadas aquelas oferecidas ao público externo pelo estado soviético, o que o motivou a buscar também outros tipos de materiais, como o testemunho direto e documentação sobre as perseguições das décadas de 1920 e 1930, dispersos “em massas de publicações de emigrados 
russos e coleções de arquivos pertencentes à época, [...].” (POSPIELOVSKY, 1987, p. XII, tradução minha).

A history of Atheism in Britain: from Hobbes to Russell é uma obra de 1988. Escrita pelo historiador David Berman, ele almejou “expor a história real do ateísmo e determinar as causas que preveniram ou encorajaram o ateísmo.” (BERMAN, 1988, p. X, tradução minha). Com foco no caso da Inglaterra, esse trabalho abarca cronologicamente da época do filósofo Thomas Hobbes (1588-1679) até o período do filósofo Bertrand Russell (1872-1970), investigando fontes que revelam a repressão ao ateísmo, os escritos onde a descrença religiosa apareceu de forma cifrada, o aparecimento do ateísmo público no final do século XVIII e seu amadurecimento filosófico no final do século XIX e início do XX com as obras de Bertrand Russell.

De 1990 é o livro Atheism in France, 1650-1729, de Alan Charles Kors. Essa obra abarca os limites cronológicos que vão da morte do filósofo René Descartes, em 1650, até o óbito e descoberta dos manuscritos ateístas do abade Jean Meslier, ocorrida em 1729. Trata-se de um estudo do comportamento intelectual do mundo erudito de língua francesa do final do século XVII e início do XVIII, com o propósito de analisar como foi que emergiu de uma comunidade que era profundamente teísta “uma corrente inequívoca e explicitamente ateísta de especulação e julgamento. Procuro entender como foi possível para aquela comunidade em particular gerar aquela corrente particular de pensamento.” (KORS, 1990, p. X, tradução minha).

Como a maioria das comunidades eruditas ao longo da história do Ocidente, a da França no início da Idade Moderna cultivava o desejo de desvendar os segredos do mundo. Esse desejo tinha como base duas grandes tradições de conhecimento, a clássica greco-romana (com ênfase na razão) e a judaico-cristã (com ênfase na fé), e tentava incessantemente chegar a um acordo com as tensões e paradoxos dessas duas formas de epistemologia. O mundo erudito da França moderna lutou com a questão fundamental em saber se o universo em que a humanidade se encontrava era eterno ou criado, aleatório ou projetado, explicável ou inexplicável pelo conhecimento natural, amoral ou justo, teleológico ou sem propósito. Em face disso, para Alan Charles Kors, esse mundo lutou com o problema do ateísmo. Por isso, "Minha tarefa é um estudo da dinâmica e das consequências desse engajamento. [...], um estudo da França moderna, da comunidade erudita e da emergência do ateísmo. É também o reconhecimento de um mundo erudito e do significado duradouro da vida mental do outro.” (KORS, 1990, p. XIII, tradução minha). 
Uma produção mais recente é Doubt, Atheism, and the nineteenth-century russian intelligentsia. Livro de autoria de Victoria Frede, foi publicado em 2011 e teve por objetivo analisar como o tema da dúvida e do ateísmo "se enraizou no pensamento e na prática de cinco gerações de intelectuais da era imperial e se tornou uma característica central, a ser celebrada ou insultada, pela intelligentsia russa.” (FREDE, 2011, p. 16, tradução minha). Aqui, a intelligentsia russa é definida com um conjunto de expectativas que enfatizava que ser uma pessoa educada no século XIX trazia consigo obrigações para com a nação e a humanidade. Neste sentido, a minoria educada da Rússia acreditava que era chamada - moralmente obrigada - a apontar para a Rússia e o mundo em geral um futuro melhor: “A enormidade desta tarefa acentuou a importância atribuída a abordar e resolver as questões eternas, pois o futuro tinha sido, até então, entendido como domínio da Providência.” (FREDE, 2011, p. 14, tradução minha).

Uma das afirmações de Victoria Frede é que os russos educados, embora influenciados pelos filósofos ocidentais, não viam como preocupação principal uma crítica filosoficamente convincente da fé em Deus. No caso deles, a experiência de vida, bem como o status político e social, também desempenharam um papel na recusa da fé. Havia o anseio em repensar os paradigmas existenciais como base para o futuro da Rússia. Contudo, os proponentes do ateísmo na intelligentsia russa não desenvolveram uma estrutura de pensamento na qual todos os vestígios da cultura cristã ortodoxa foram erradicados. Ao contrário, “eles continuamente recorreram ao vocabulário de fé e salvação para articular o significado que a vida do incrédulo deve ter. De uma perspectiva filosófica, seus comentários sobre a dúvida e o ateísmo que defendiam careciam de rigor, mas isso não os privava de força.” (FREDE, 2011, p. 12, tradução minha).

Battling the gods: Atheism in the ancient world, é um trabalho de 2016 de autoria do historiador Tim Whitmarsh. Esse livro busca oferecer uma perspectiva analítica diferente daquela que compreende o fenômeno da descrença religiosa como produto da modernidade europeia, seja da parte de alguns ateus, que a entendem como consequência do Estado secular e do avanço do método científico, seja da parte de alguns religiosos, que a entendem como produto da degradação ocidental consumida pelo modo de vida capitalista. Para Tim Whitmarsh, o ateísmo seria comprovadamente pelo menos tão antigo quanto as religiões de Abraão, o que significa considerá-lo pelo menos tão longevo quanto o monoteísmo do povo de Israel: 
Estou persuadido por aqueles que veem o monoteísmo na forma bíblica que o conhecemos hoje como moldado pelo retorno dos exilados israelitas no período do Segundo Templo (após as conquistas do rei persa Ciro o Grande em 539 a.c). É mais ou menos na época em que encontramos na Grécia as primeiras articulações filosóficas do ceticismo em relação à religião tradicional, nos escritos de Xenófanes de Cólofon (570-475 a.c). (WHITMARSH, 2017, p. 07, tradução minha).

A história do ateísmo retratada nas páginas desse livro recobre um longo período de mil anos, tendo como pano de fundo grandes mudanças históricas: a emergência da Grécia Antiga de sua "Idade das Trevas" em um mundo de cidades-estados letradas; o desenvolvimento da cidadania e da democracia; as conquistas de Alexandre, o Grande, e a fragmentação de seu Império; a subsunção do mundo de língua grega ao Império Romano; e, finalmente, a chegada do Cristianismo. Ainda que o ceticismo em relação ao universo religioso no período antigo não tenha sido exclusividade da civilização greco-romana, Tim Whitmarsh (2017) afirma que é dela que foram preservadas mais fontes sobre o tema, como cultura material, arte, inscrição de pedra e papiro.

O alvo do livro é um segmento relativamente pequeno da sociedade antiga: “A maioria dos citados nestas páginas eram homens educados das camadas superiores da vida grega e romana (não porque o ateísmo seja uma prerrogativa exclusivamente masculina da elite, mas porque aquela estreita faixa demográfica está desproporcionalmente representada em nossas fontes).” (WHITMARSH, 2017, p. 08, tradução minha). Essa meta é complementada com a seguinte afirmação: “Este livro representa, portanto, uma espécie de arqueologia do ceticismo religioso. É em parte uma tentativa de escavar o ateísmo antigo de debaixo dos escombros empilhados sobre ele por milênios de opróbrio cristão.” (WHITMARSH, 2017, p. 11, tradução minha).

A historiadora Victoria Smolkin publicou em 2018 o livro A sacred space is never empty: a history of soviet atheism. O propósito dessa obra foi analisar a história do ateísmo soviético desde a Revolução Bolchevique de 1917 até o retorno da religião à vida pública nos anos finais da URSS. De acordo com V. Smolkin (2018), os estudos sobre a história do ateísmo soviético tendem a enfatizar que o projeto soviético era uma religião política, uma utopia fracassada ou uma versão particular da modernidade secular. Essas narrativas, quando tomadas separadamente seriam incompletas e, quando tomadas em conjunto, confirmariam, mas não iluminariam, as transformações nas abordagens soviéticas da religião e do ateísmo entre 1917 e 1991. 
Para Victoria Smolkin (2018), os bolcheviques, nos seus esforços para reconstruir o mundo, procuraram remover a religião dos “espaços sagrados” da vida soviética, fossem as instituições religiosas, a teologia ou o modo de vida inspirada nelas, oferecendo como alternativa o Partido Comunista e sua ideologia marxista-leninista. Diante disso, o ateísmo foi reimaginado de maneiras fundamentais, em distintas conjunturas históricas: da repressão antirreligiosa e do "ateísmo militante" do início do período soviético à reaproximação de Stalin com a religião em 1943; da remobilização da campanha contra a religião por Nikita Khrushchev e o "ateísmo científico" entre 1953 e 1964; da retirada de Leonid Brejnev da utopia ideológica na União Soviética entre 1964 e 1982 a ruptura de Gorbachev com o ateísmo e o retorno da religião à vida pública em 1988. Portanto, “o ateísmo soviético, então, tem sua própria história - uma que está entrelaçada, mas é distinta da história da religião.” (SMOLKIN, 2018, p. 03-04, tradução minha).

A última referência de uma produção historiográfica estrangeira que gostaria de expor é o livro Race in a godless world: atheism, race, and civilization, 1850-1914. Esta obra foi publicada no ano de 2019 pelo historiador Nathan G. Alexander e possui como objetivo principal "investigar como as ideias sobre raça, ateísmo e civilização - as quais atingiram seu ápice de várias maneiras no século XIX - estavam interconectadas.” (ALEXANDER, 2019, p. 03, tradução minha). De acordo com Nathan G. Alexander (2019), existem dois argumentos que buscam dar sentido a relação entre secularização e racismo. Um argumento afirma que a secularização contribuiu para o desenvolvimento do racismo. O cristianismo sustentava que todos os humanos tinham sido criados à imagem de Deus, ou seja, todos os humanos eram literalmente iguais. Conforme a influência da religião cristã começou a declinar nos séculos XVIII e XIX, “os humanos não eram mais vistos como parte de uma grande família criada por Deus, mas sim como nada mais do que outra espécie de animal.” (ALEXANDER, 2019, p. 01, tradução minha).

Já o outro argumento defende que a secularização ofereceu novas ferramentas para se opor ao racismo. Nessa perspectiva, a religião desempenhou papel crucial no surgimento do racismo através de sua longa história de antissemitismo e desrespeito pelas religiões não-cristãs. Os africanos, por exemplo, foram considerados pagãos irredimíveis e separados dos brancos cristãos. Em contraste, “a secularização poderia ser vista como um benefício para a luta contra o racismo, uma vez que despojou as ideias cristãs irracionais sobre a humanidade e as substituiu por outras baseadas na ciência e na razão.” (ALEXANDER, 2019, p. 02, tradução minha). No caso: 


\begin{abstract}
Essas duas perspectivas conflitantes sobre a relação entre secularização e racismo cada uma com um certo grau de verdade - focam principalmente na influência das ideias cristãs sobre raça. Eles apontam para a necessidade de um exame das visões raciais dos ateus, um tópico que nenhum historiador ainda abordou em detalhes. Este livro aborda precisamente essa questão. (ALEXANDER, 2019, p. 02, tradução minha).
\end{abstract}

O recorte cronológico da pesquisa do livro é a segunda metade do século XIX e o início do século XX na Grã-Bretanha e nos Estados Unidos. Nathan G. Alexander (2019) oferece dois motivos para isso: por um lado, foi a época em que as atitudes racistas na Grã-Bretanha e nos Estados Unidos alcançaram proeminência com a ciência racial e sua ênfase nas classificações raciais com base em características físicas e mentais; por outro lado, este período viu um crescente movimento popular de ateus e outros descrentes em ambos os lados do Atlântico, que desafiou o autoridade do cristianismo e da Bíblia e defendeu uma visão racional e científica do mundo. Esse grupo social se inseriu na esfera pública por meio de "inúmeras palestras, livros, panfletos, debates e jornais semanais que visavam atingir um amplo público.” (ALEXANDER, 2019, p. 03, tradução minha). Esse material de divulgação foi uma importante fonte para esse livro.

\title{
O ATEÍSMO NA HISTORIOGRAFIA BRASILEIRA
}

O ateísmo como um elemento constitutivo da história do Brasil ou da trajetória de outros países ainda é alvo de pouco interesse investigativo por parte da comunidade historiográfica brasileira. E os estudos que encontrei até o momento são produtos de anos recentes e realizados na forma de monografias de conclusão de curso de graduação e dissertações de mestrado. Aqui eu gostaria de aprofundar uma discussão feita por mim em um trabalho recente (cf. SILVA, 2018).

Em relação as monografias sobre história do ateísmo, a com data mais antiga que achei foi Reprodução sob condições controladas: o ateísmo como movimento social nos materiais de divulgação do Templo Positivista de Porto Alegre. Esse trabalho é de autoria de Ricardo Cortez Lopes e foi apresentada como requisito para conclusão do Curso de Bacharelado em História na Universidade Federal do Rio Grande do Sul em 2010. De acordo com Lopes (2010, p. 09) “o Positivismo Comteano foi a primeira força de expressão coletiva e pública do ateísmo em território nacional.” O filósofo francês Auguste Comte (1798-1857) teria desenvolvido um pensamento ateísta ao teorizar sobre a realidade mundana como produto de um processo 
evolutivo onde a religião seria uma forma arcaica de entender o mundo a ser superada pela ciência.

O pensamento filosófico comteano exerceu significativa influência na elite intelectual brasileira entre fins do século XIX e início do XX. Para Ricardo Cortez Lopes (2010), o positivismo comteano permitiu que o ateísmo se tornasse, pela primeira vez, uma expressão coletiva e pública no Brasil. Ele exemplifica isso com a investigação das ações articuladas pelo Templo Positivista de Porto Alegre, fundado em 1912, o que originou um movimento social ateu, e análise de suas ideias veiculadas através de materiais de divulgação, como revistas, panfletos, ensaios e romances, produzidos por essa instituição nas primeiras décadas do século XX.

A segunda monografia que encontrei em minhas pesquisas é de autoria da historiadora Kélen Aparecida Vieira. O título do trabalho é www.atea.org.br (Associação Brasileira de Ateus e Agnósticos): Ateísmo, identidades culturais e não religiosas na sociedade contemporânea, e data de 2014. Nesse trabalho foi abordada a atuação da Associação Brasileira de Ateus e Agnósticos (ATEA), uma associação de perfil ateísta criada em 2008, tendo como pano de fundo o aumento no percentual da população no Brasil que declara não possuir crença religiosa. Kélen Aparecida Vieira (2014) também destaca que o advento da internet comercial no Brasil a partir da década de 1990 proporcionou a oportunidade para ateus e ateias espalhados em um imenso território nacional interagirem de forma rápida através do compartilhamento de textos e fóruns de discussão. Contudo, “muitos ateus desejavam ir muito mais além do mundo virtual, buscando mudanças no mundo real, especialmente mudanças nas maneiras como os ateus são vistos pela sociedade e como o estado se relaciona com a religião” (VIEIRA, 2014, p. 35).

Já no quesito dissertação de mestrado sobre história do ateísmo destaco primeiramente o trabalho de Maria Helena Azevedo Ferreira: Ateísmo, neoateísmo e o “problema” da religião no século XXI: uma análise da obra Deus, um delírio (2007) de Richard Dawkins. Essa pesquisa de pós-graduação é de 2017 e aborda o fenômeno do ateísmo não diretamente relacionado a história do Brasil. A historiadora propôs fazer uma análise do discurso sobre ateísmo e religião na obra Deus, um delírio, publicada originalmente em 2006, com o objetivo de “pensar como um intelectual ateu do século XXI, Richard Dawkins, constrói seu discurso sobre religiões, e como este se desdobra em um discurso acerca do ateísmo.” (FERREIRA, 2017, p. 16). Para ela, Richard Dawkins faria parte de um ateísmo midiático, marcado pelo grande alcance de sua mensagem, e sob o impacto dos atentados realizados contra os EUA em 
2001 por fundamentalistas islâmicos. Nesse sentido, “a religião se configura como 'problema' para Dawkins, entendidas como um entrave para o progresso do conhecimento, principalmente nos ecos do mundo islâmico no Ocidente e na própria sociedade ocidental, [...].” (FERREIRA, 2017, p. 19).

A segunda dissertação de mestrado que gostaria de referenciar é do ano de 2018 e de autoria de Danilo Monteiro Firmino. Com o título Associação Brasileira de Ateus e Agnósticos (ATEA) x Estado brasileiro: ateísmo, laicidade e conflitos jurídicos na formação do primeiro movimento social ateísta do Brasil, o autor defende a hipótese de que a ATEA é o primeiro movimento social ateu brasileiro e que se caracteriza por uma militância em torno da defesa do ateísmo e da laicidade do Estado no Brasil, atuando principalmente por meio do poder judiciário para atingir seus objetivos. O ateísmo da ATEA estaria amparado na crença no poder da razão, na explicação da natureza por via naturalista e materialista, um legado intelectual iluminista do século XVIII (base intelectual antiga), e nos pressupostos teóricos do atual neoateísmo na cena internacional (base intelectual contemporânea). Danilo Monteiro Firmino define a luta da ATEA como uma disputa pelo poder com o intuito de transformar o Estado brasileiro em uma instituição verdadeiramente laica, o que, de acordo com a ATEA, não era o caso. (FIRMINO, 2018).

Por fim, uma breve palavra sobre $O$ ateísmo no Brasil: os sentidos da descrença nos séculos XX e XXI. Essa é uma obra publicada por mim em 2020 com o objetivo de oferecer um quadro cronológico amplo, ainda que incompleto, sobre a história do ateísmo brasileiro entre o início do século XX e as duas primeiras décadas do século XXI. Com base nos pressupostos do domínio da história intelectual, “A ênfase maior deste livro foi investigar de que maneira os indivíduos, grupos e associações deram sentido ao ateísmo na história do Brasil” (SILVA, 2020, p. 09).

Nesse estudo eu priorizei três tradições ateístas em solo brasileiro: a anarquista, fruto da confluência de duas tradições intelectuais, o anticlericalismo e o anarquismo, e que deu "origem a uma concepção de ateísmo que identificou as religiões e as instituições religiosas como estruturas de poder que legitimavam e exerciam uma dominação cerceadora da liberdade dos indivíduos” (SILVA, 2020, p. 10); a marxista de vertente leninista, expresso em termos partidários pelo Partido Comunista do Brasil (PCB), criado em 1922. Segundo essa tradição intelectual, “as crenças e instituições religiosas seriam frutos de formas específicas de organização social e econômica das sociedades, sendo essas formas de organização a base da 
intepretação materialista do marxismo sobre a religião e o ateísmo” (SILVA, 2020, p. 11); Por fim:

O ateísmo brasileiro no início do século XXI apresenta a última parte desta pesquisa. O objetivo deste quarto e último capítulo é compreender a maneira pela qual o ateísmo tem sido definido a partir do florescimento do ativismo ateísta no Brasil. A bibliografia e as fontes indicam a preponderância nas duas primeiras décadas do século XXI do ateísmo cientificista, ou seja, uma visão de mundo fundamentada no saber proveniente das ciências naturais, especialmente o evolucionismo darwinista (SILVA, 2020, p. 11).

Para finalizar, eu queria registrar que defendo a posição de que o ateísmo possui uma história própria, distinta da história das religiões, ainda que com ela mantenha um diálogo. O que pensam as pessoas que rompem com uma crença religiosa? Que visões de mundo elas elaboram e como isso impacta nas relações sociais e na presença no espaço público? Esses questionamentos me parecem produtivos para pensar uma autonomia do ateísmo em relação aos credos religiosos. Nesse sentido eu fui influenciado por Georges Minois (2014), adepto dessa posição, e a partir da qual formulou a ideia de um ateísmo teórico (uma reflexão intelectual sobre a descrença) e de um ateísmo prático (uma prática cotidiana sem referências religiosas) e por Stephen LeDrew (2016), que traçou a história do ateísmo moderno, com origem no Iluminismo do século XVIII, o qual moldou uma visão de mundo calcada na racionalidade e no secularismo, influenciando tradições científicas e filosóficas no século XIX e XX.

\section{CONSIDERAÇÕES FINAIS}

As pesquisas historiográficas sobre o ateísmo que eu pontuei no decorrer desse artigo foram selecionadas com o propósito de mostrar aos leitores brasileiros a potencialidade de uma investigação sobre esse tema. Reconheço que as obras que citei não oferecem um quadro completo dos trabalhos que possivelmente já foram produzidos por historiadores estrangeiros e nacionais. Contudo, eles são um indicativo de que é possível fazer esse tipo de estudo. E torço para que a comunidade historiográfica brasileira olhe com mais carinho esse âmbito da realidade humana.

Os desafios ainda são enormes para quem tem interesse em trabalhar com o ateísmo. Os autores que eu citei nesse artigo são unânimes em afirmar o histórico preconceito que recaiu, e ainda hoje se faz presente, sobre aqueles e aquelas que duvidaram ou não reconheceram a existência de uma divindade. No passado, isso até mesmo fez com que essas pessoas 
preferissem ocultar seu pensamento, o que dificulta para o historiador do presente encontrar fontes para sua pesquisa. Por outro lado, nas últimas décadas do século XX o fenômeno da descrença religiosa ganha espaço em diversas sociedades, inclusive no Brasil. Por isso, não me parece coincidência que os trabalhos sobre essa temática tenham se intensificado nos últimos anos. O dossiê da revista Relegens Thréskeia que contempla meu artigo sinaliza o anseio para um novo espaço de pesquisa nas ciências sociais. Que os historiadores se sintam inspirados com isso.

\section{REFERÊNCIAS BIBLIOGRÁFICAS}

ALEXANDER, Nathan G. Race in a godless world: atheism, race, and civilization, 18501914. Manchester: Manchester University Press, 2019.

BERMAN, David. A history of Atheism in Britain: from Hobbes to Russell. London: Routledge, 1988.

CERTEAU, Michel de. A escrita da história. Rio de Janeiro: Forense Universitária, 2008.

FERREIRA, Maria Helena Azevedo. Ateísmo, neoateísmo e o “problema” da religião no século XXI: uma análise da obra Deus, um delírio (2007) de Richard Dawkins. 2017. Dissertação (Mestrado em História) - Departamento de História, Universidade Estadual de Maringá, Maringá.

FIRMINO, Danilo Monteiro. Associação Brasileira de Ateus e Agnósticos (ATEA) x Estado Brasileiro: ateísmo, laicidade e conflitos jurídicos na formação do primeiro movimento social ateísta do Brasil. 2018. Dissertação (Mestrado em História) - Faculdade de Formação de Professores, Universidade do Estado do Rio de Janeiro, São Gonçalo.

FREDE, Victoria. Doubt, Atheism, and the Nineteenth-Century Russian Intelligentsia. Madison: University of Wisconsin Press, 2011.

KORS, Alan Charles. Atheism in France, 1650-1729. Vol. I: the orthodox sources of disbelief. New Jersey: Princeton University Press, 1990.

LAPA, José Roberto do Amaral. História e historiografia: Brasil pós-64. Rio de Janeiro: Paz e Terra, 1985.

LEDREW, Stephen. The Evolution of Atheism: The Politics of a Modern Movement. Nova York: Oxford University Press, 2016.

LOPES, Ricardo Cortez. Reprodução sob condições controladas: o ateísmo como movimento social nos materiais de divulgação do Templo Positivista de Porto Alegre. 2010. Monografia (Bacharelado em História) - Departamento de História, Universidade Federal do Rio Grande do Sul. Porto Alegre. 
MINOIS, Georges. História do ateísmo: os descrentes no mundo ocidental, das origens aos nossos dias. São Paulo: Editora Unesp, 2014.

POSPIELOVSKY, Dimitry V. A history of marxista-leninist Atheism and soviet antireligious policies. Vol. 1. A history of soviet Atheism in theory and practice, and the believer. New York: St. Martin’s Press, 1987.

RODRIGUES, Denise dos Santos. Os sem religião nos censos brasileiros: sinal de uma crise do pertencimento institucional. Horizonte, Belo Horizonte, vol. 10, $\mathrm{n}^{\circ}$ 28, p. 1130-1153, out./dez. 2012.

RÜSEN, Jörn. História viva. Teoria da História III: formas e funções do conhecimento histórico. Brasília: Editora Universidade de Brasília, 2007.

SILVA, Rafael Rodrigues da. O campo religioso brasileiro: historiografia e religiosidade. Alguns apontamentos. Revista Lusófona de Ciências da Religião, Lisboa, ano VI, ${ }^{\circ}$ 12, p. 133-139, 2007.

SILVA, Ricardo Oliveira da. Será que chegou a hora e a vez do ateísmo na historiografia brasileira? Revista História em Reflexão. Dourados, vol. 12, nº 24, p. 280-308, jul./dez. 2018.

SILVA, Ricardo Oliveira da. O ateísmo no Brasil: os sentidos da descrença nos séculos XX e XXI. Jundiaí, SP: PACO Editorial, 2020.

SMOLKIN, Victoria. A sacred space is never empty: a history of soviet atheism. New Jersey: Princeton University Press, 2018.

THROWER, James. Breve história do ateísmo ocidental. Lisboa: Edições 70, 1982.

VIEIRA, Kélen Aparecida. WWW.atea.org.br (Associação Brasileira de Ateus e Agnósticos). Ateísmo, identidades culturais e não religiosas na sociedade contemporânea. 2014. Monografia (Graduação em História) - Instituto de História, Universidade Federal de Uberlândia, Uberlândia.

WHITMARSH, Tim. Battling the gods: atheism in the ancient world. London: Faber \& Faber Ltd, 2017. 